\title{
Insight into the Binding of DFG-out Allosteric Inhibitors to B-Raf Kinase Using Molecular Dynamics and Free Energy Calculations
}

\author{
Luis Coronel ${ }^{\mathrm{d}}$, José M. Granadino-Roldán ${ }^{\mathrm{b}}$, Marta Pinto ${ }^{\mathrm{a}}$, \\ M.Santos Tomas ${ }^{\mathrm{c}}$, M. Dolors Pujol ${ }^{\mathrm{d}}$, Jaime Rubio-Martinez ${ }^{{ }^{\mathrm{a}}}$
}

${ }^{a}$ Department of Physical Chemistry, University of Barcelona and the Institut de Recerca en Quimica Teorica i Computacional (IQTCUB), Barcelona, Spain

${ }^{b}$ Departamento de Química Física y Analítica, Facultad de Ciencias Experimentales, Universidad de Jaén, Paraje las Lagunillas, s/n. 23071, Jaén, Spain

${ }^{c}$ Sec. Matemàtiques i Informàtica ETSAB, Universitat Politècnica de Catalunya (UPC),

ETS d'Arquitectura, Av. Diagonal 649, 08028 Barcelona, Spain

${ }^{d}$ Laboratori de Química Farmacèutica (Unitat Associada al CSIC). Facultat de Farmàcia, Universitat de Barcelona, Av. Diagonal 643, E-08028 Barcelona, Spain

Keywords: B-Raf; DFG-out; Drug design; MM-PB/GBSA; Molecular dynamics; Type II inhibitors

\footnotetext{
* To whom correspondence should be addressed

Jaime Rubio-Martinez

Phone: 34-93-4039263

Fax: 34-93-4021231

e-mail: jaime.rubio@ub.edu
} 


\section{ABSTRACT}

B-Raf mutations are identified in $40-50 \%$ of patients with melanoma and among them, the substitution of valine for glutamic acid at position $600\left({ }^{\mathrm{V} 600 \mathrm{E}} \mathrm{B}-\mathrm{Raf}\right)$ is the most frequent. Treatment of these patients with BRaf inhibitors has been associated with a clear clinical benefit. Unfortunately, multiple resistance mechanisms have been identified and new potent and selective inhibitors are currently needed. In this work, five different type II inhibitors, which bind ${ }^{\mathrm{V} 600 \mathrm{E}} \mathrm{B}-\mathrm{Raf}$ in its DFG-out conformation, have been studied using molecular dynamics, free energy calculations and energy decomposition analysis. The ranking of calculated MMPB/GBSA binding affinities is in good agreement with the experimentally measured ones. The per-residue

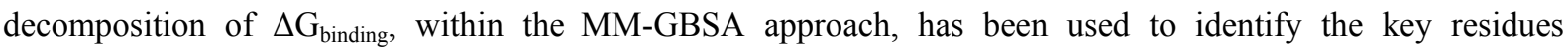
governing the allosteric binding of the studied compounds to the ${ }^{\mathrm{V} 600 \mathrm{E}} \mathrm{B}-\mathrm{Raf}$ protein kinase. Results indicate that although van der Waals interactions are key determinants for binding, hydrogen bonds also play an important role. This work also provides a better structural understanding of the binding of DFG-out inhibitors to ${ }^{\mathrm{V} 600 \mathrm{E}} \mathrm{B}-$ Raf, which can be used in a further step for rational design of a new class of B-Raf potent inhibitors. 
GRAPHICAL ABSTRACT

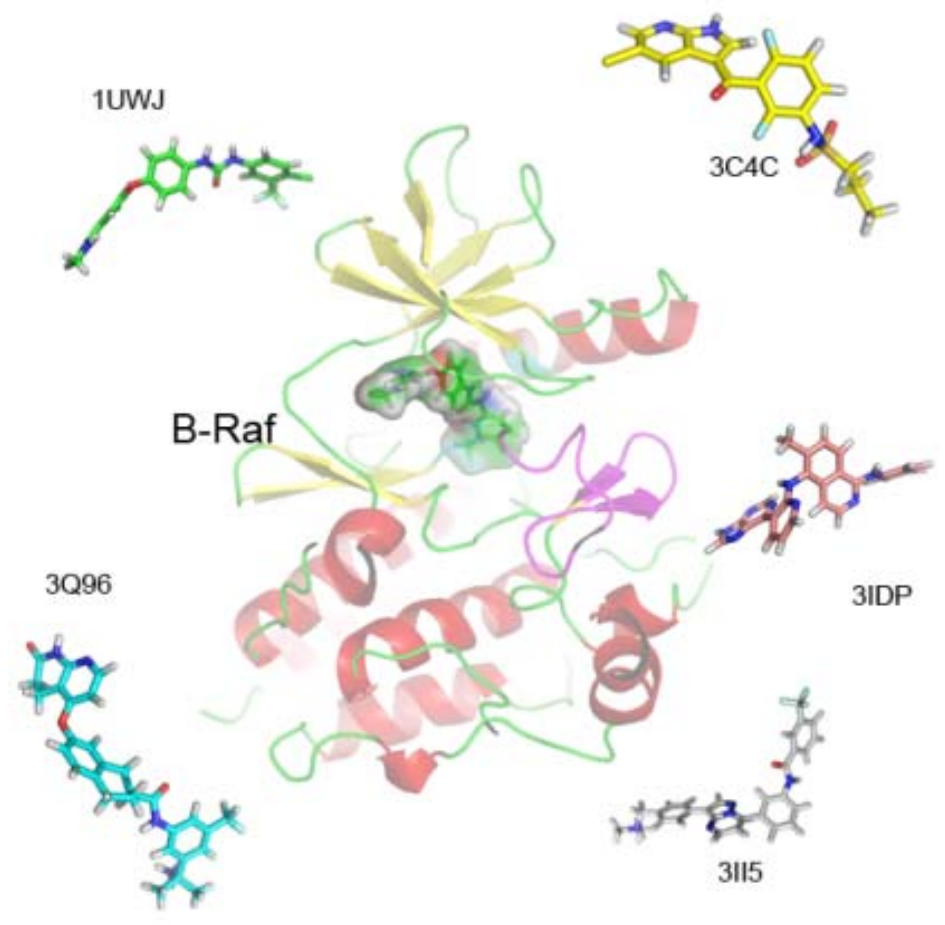




\section{INTRODUCTION}

The mitogen-activated protein kinase signal transduction pathway (MAPK) regulates cell growth, proliferation and differentiation in response to growth factors, cytokines and hormones. Importantly, the gain or loss of function of key elements in this signaling pathway has been related with the appearance and development of many types of cancer. One of these key elements is the Ras activating factor (RAF) family of serine/threonine kinases, composed by the isoforms A-Raf, B-Raf and C-Raf, which with the downstream molecules MEK and ERK constitute the MAPK signaling pathway. Activation of B-Raf is produced by binding to Ras, whereas Aand C-Raf activation requires additional signaling.

While mutations in A-Raf and C-Raf are rare in human cancer, mutations of B-Raf have been detected in many types of cancer such as thyroid, colorectal, ovarian or melanomas [1]. Among them, the substitution of valine for glutamic acid at position 600 in the activation segment, adjacent to the kinase conserved DFG motif (residues 594-596), accounts for $90 \%$ of B-Raf mutations in human cancers [2]. This mutation renders the kinase constitutively active, being 700-fold more active than the wild type [3] and independent of Ras function. Because of these findings, ${ }^{\mathrm{V} 600 \mathrm{E}} \mathrm{B}-\mathrm{Raf}$ has emerged as an attractive target for cancer treatment.

Two different conformational states have been characterized for B-Raf. In the active state, also known as DFG-in, residue D594 chelates the magnesium cation that interacts with the two phosphate groups of ATP. Rotation of this residue switches the enzyme to the inactive state, also called DFG-out and characterized by the orientation of F595 towards the ATP-binding site. This change in orientation of phenylalanine not only blocks the binding of the nucleotide to the enzyme [4], but also exposes an additional hydrophobic binding group adjacent to the ATP binding site, which is also known as allosteric site [5].

In recent years many efforts have been made to develop B-Raf inhibitors. These inhibitors can be classified into two different types [6]. Type I inhibitors recognize the active conformation of the kinase and act as ATP-competitive inhibitors, whereas type II B-Raf inhibitors stabilize the inactive conformation of the enzyme.

Sorafenib (Nexavar), approved by the FDA for use in the treatment of advanced renal cell carcinoma (RCC) and hepatocellular carcinoma (HCC) [7] was the first ${ }^{\mathrm{V} 600 \mathrm{E}} \mathrm{B}-\mathrm{Raf}$ inhibitor. This inhibitor stabilizes the enzyme in its DFG-out conformation. Unfortunately, this drug presented ineffective results in clinical trials for melanoma [8], which led to the emergence of a second-generation of inhibitors including Vemurafenib (PLX4032), Dabrafenib and LGX818, which in contrast to Sorafenib, binds to ${ }^{\mathrm{V} 600 \mathrm{E}} \mathrm{B}-\mathrm{Raf}$ in its active or DFG-in conformation [9]. However, acquired resistance to B-Raf inhibitor treatment [10] points out the need for the development of new inhibitors [11].

Structure-based drug design has emerged as an attractive and promising approach and has been successfully applied in many drug discovery projects $[12,13]$. Different studies have been done describing the design of a novel series of ${ }^{\mathrm{V} 600}$ EB-Raf inhibitors via structure-based methods [14-18]. But, to data, only few studies have been done applying this approach to the specific analysis of ${ }^{\mathrm{V} 600} \mathrm{~EB}-\mathrm{Raf} /$ ligand interactions. Mayor parts of them are centered in the pharmacophore and binding analysis of ${ }^{\mathrm{V} 600 \mathrm{E}} \mathrm{B}$-Raf inhibitors acting basically in the DFG-in conformation [19-22]; other are mainly based in the docking and posterior analysis by molecular dynamics of some DFG-out inhibitors [23-26] or on a purely 3D-QSAR approach [27]. But, none of them make 
a specific and deeper comparison of available experimental structures of ${ }^{\mathrm{V} 600 \mathrm{E}} \mathrm{B}-\mathrm{Raf} /$ ligand systems in the DFGout conformation.

Thus, this work is aimed at identifying the interactions that govern the binding of five different type II inhibitors to ${ }^{\mathrm{V} 600 \mathrm{E}} \mathrm{B}-\mathrm{Raf}$ in its DFG-out conformation using molecular dynamics (MD), MM-PB/GBSA free energy calculations and MM-GBSA free energy decomposition analysis. Moreover, the availability of the corresponding experimental complexes in the Protein Data Bank avoids any bias introduced by an incorrect selection of docking poses, allowing us to identify the key structural features responsible for the binding to

${ }^{\mathrm{V} 600 \mathrm{E}} \mathrm{B}$-Raf in its DFG-out conformation. This information can be used in a further step for rational design of a new class of potent inhibitors.

\section{MATERIALS AND COMPUTATIONAL METHODS}

The ff99SB [28] and gaff [29] force fields, as implemented in the AMBER v.11 [30] suite of programs were used to model the protein and the ligands, respectively. Molecular simulations were carried out under periodic boundary conditions using the particle-mesh-Ewald method [31] for the treatment of the long-range electrostatic interactions. A cutoff distance of $10 \AA$ was selected to compute the non-bonded interactions and the solvent was considered explicitly using TIP3P [32] water molecules with a minimum distance from the edge of the box of $15 \AA$ and removing those water molecules closer than $1.8 \AA$ from any atom. Counterions were added, when necessary, to neutralize the systems.

To prepare the systems, analyze the root mean square fluctuation (rmsf), identify intermolecular hydrogen bonds, van der Waals and electrostatic interactions, obtain total binding free energies and analyze the contribution of each receptor residue to the total binding free energy for all the studied complexes during the production time, the Antechamber, LEaP, ptraj and MMPBSA.py modules of AmberTools12 package [30] were used. All figures were rendered with the Pymol graphics program [32].

\subsection{Preparation of the complexes}

The chemical structures and the reported $\mathrm{IC}_{50}$ inhibitory values for the five DFG-out inhibitors studied in this work are shown in Figure 1. The atomic coordinates of the five complexes with ${ }^{\mathrm{V} 600 \mathrm{E}} \mathrm{B}$-Raf were retrieved from the Protein Data Bank (PDB entries: 1UWJ [3], 3C4C [34], 3IDP [35], 3II5 [36], 3 Q96 [237]). In the case of the 1UWJ and 3Q96 complexes, only one of the two asymmetrically packed kinase-inhibitor complexes of the crystallographic unit was selected for further studies. In the case of the $3 \mathrm{C} 4 \mathrm{C}$ structure the DFG-out unit was selected. After removing water molecules and counterions, the missing residues of these structures, corresponding to a loop located in the vicinity of the kinase conserved DFG motif (from residues 596 to 613), were modeled using the MOE homology modelling module [38] and the primary sequence of wild type B-Raf protein with an introduced V600E mutation. For each complex, only the lowest energy model was considered for further studies. However, none of the studied complexes modeled through minimization and molecular dynamics $(20 \mathrm{~ns})$ reached the convergence expected for systems using as initial structure one coming from an $\mathrm{x}$-ray experiment : An analysis of the MD trajectories using the VMD [39] program exposed an excessive freedom of the loop caused by the lack of secondary structure. In order to overcome this problem, new coordinates for the 
missing loop were obtained from the coordinates of the equivalent residues of the c-Abl protein (PDB entry 1IEP [40] ), superposing the main atoms of the first and the last residues of the missing loop of both structures. Next, all five systems were prepared for subsequent calculations using the LEaP module of Amber v.11 as previously stated.

\section{$2.2 \quad$ Energy minimization}

The five complexes were energy minimized before molecular dynamics in order to remove possible steric clashes and adapt the systems to the force field using a four-step procedure. In the first step, the protein and the ligand were fixed and only water molecules and counterions were allowed to relax. In a second step, also the side chains were minimized, keeping the backbone and the ligand frozen. Next, only the backbone of the protein was kept frozen. Finally, the complexes were energy minimized until the final root mean square (rms) energy gradient was lower than $1 \mathrm{kcal} / \mathrm{mol}$.

\subsection{Simulated annealing}

In order to obtain a better adaptation of the modeled loop to each particular complex, the structures obtained at the end of the four-step minimization procedure were subjected to one cycle of simulated annealing. During this procedure, all the atoms of the system, except those belonging to the modeled loop, were kept frozen. The annealing was carried out using a multi-step procedure: (1) the temperature of the system was increased to $300 \mathrm{~K}$ at a constant rate of $30 \mathrm{~K} / 10 \mathrm{ps}$ within the NVT ensemble; (2) at $300 \mathrm{~K}$, the density of the system was equilibrated by carrying out 400 ps of simulation in the NPT ensemble; (3) then, 1 ns of simulation was performed within the NVT ensemble; (4) after this time, the temperature of the system was gradually decreased at a constant rate of $30 \mathrm{~K} / 10 \mathrm{ps}$; (5) finally, the system was energy minimized without any restriction for 5000 cycles of steepest descents. Then, the obtained minimized structures were used as starting point for the MD simulations.

\subsection{Molecular dynamics simulations}

The minimized structures were gradually heated within the NVT ensemble from 0 to $300 \mathrm{~K}$ during 200 ps at a constant rate of $30 \mathrm{~K} / 20 \mathrm{ps}$ using the Berendsen's algorithm [41] with a time coupling constant of $0.2 \mathrm{ps}$. During the heating procedure, all the backbone atoms excluding those of the modeled loop were constrained to their initial positions using a force constant of $0.1 \mathrm{kcal} / \mathrm{mol} \AA$. The SHAKE algorithm was employed on all atoms covalently bonded to hydrogen atoms, allowing an integration time step of $2 \mathrm{fs}$. Finally, a MD production run within the NVT ensemble of $30 \mathrm{~ns}$ was performed for each system at a constant temperature of $300 \mathrm{~K}$. The coordinates of the trajectories were saved every 2 ps throughout the simulation. Binding free energy and hydrogen bond analyses were performed for the last $5 \mathrm{~ns}$ of simulation using 500 snapshots. However, the convergence of the binding free energy was checked calculating these values for the whole MD, with MMPBSA and MM-GBSA, using this time 100 snapshots, extracted each $10 \mathrm{ps}$, for each ns of MD. 


\subsection{Binding Free energy calculations}

Binding free energies $\left(\Delta \mathrm{G}_{\mathrm{b}}\right)$ were calculated using the Molecular Mechanics Generalized Born Surface Area (MM-GBSA) and the Molecular Mechanics Poisson-Boltzmann Surface Area (MM-PBSA) algorithms as implemented in AmberTools12. According to these approaches, the total binding free energy can be calculated using the equation:

$$
\Delta \mathrm{G}_{\mathrm{b}}=\Delta \mathrm{H}^{\mathrm{gas}}+\Delta \mathrm{G}^{\mathrm{solv}}-\mathrm{T} \Delta \mathrm{S}
$$

where $\Delta \mathrm{H}^{\text {gas }}$, the gas phase interaction energy, is calculated as the sum of the internal energy $\left(\Delta \mathrm{H}_{\text {int }}\right)$ and two non-bonded terms corresponding to the van der Waals $\left(\Delta \mathrm{H}_{\mathrm{vdW}}\right)$ and electrostatic $\left(\Delta \mathrm{H}_{\mathrm{elec}}\right)$ molecular mechanics energies:

$$
\Delta \mathrm{H}^{\text {gas }}=\Delta \mathrm{H}_{\mathrm{int}}+\Delta \mathrm{H}_{\mathrm{vdW}}+\Delta \mathrm{H}_{\mathrm{elec}}
$$

The solvation free energy $\left(\Delta \mathrm{G}^{\text {solv }}\right)$ is obtained by summing the polar $\left(\Delta \mathrm{G}_{\text {polar }}\right)$ and nonpolar $\left(\Delta \mathrm{G}_{\text {nonpolar }}\right)$ terms:

$$
\Delta \mathrm{G}^{\text {solv }}=\Delta \mathrm{G}_{\text {polar }}+\Delta \mathrm{G}_{\text {nonpolar }}
$$

The $\Delta \mathrm{G}_{\text {polar }}$ can be calculated solving the Poisson-Boltzmann (PB) equation or using the Generalized Born (GB) method. In the present work, we used the Onufriev-Bashford-Case (OBC) generalized Born [42] $(\mathrm{igb}=5)$ as implemented in AmberTools12. The nonpolar contribution $\left(\Delta \mathrm{G}_{\text {nonpolar }}\right)$ is calculated from the solvent accessible surface area (SASA) according to the equation:

$$
\Delta \mathrm{G}_{\text {nonpolar }}=\gamma \mathrm{SASA}+\beta
$$

where the values for $\gamma$ and $\beta$ were set to $0.00542 \mathrm{kcal} / \mathrm{mol} \AA^{2}$ and $0.9200 \mathrm{kcal} / \mathrm{mol}$ in the MM-PBSA [43] approach, and to $0.0072 \mathrm{kcal} / \mathrm{mol} \AA^{2}$ and $0 \mathrm{kcal} / \mathrm{mol}$ in MM-GBSA [44]. Values for interior and exterior dielectric constants were set to 1 and 80 , respectively.

The entropic contribution to the total binding free energy was computed within the harmonic entropy approximation using the normal mode analysis (NMA) implemented in Ambertools12. Because of the high computational requirements, the entropic contribution was averaged over 100 snapshots extracted at a time interval of $50 \mathrm{ps}$ from the last $5 \mathrm{~ns}$ of each trajectory.

\subsection{Multiple molecular dynamics}

For each one of the five different ${ }^{\mathrm{V} 600 \mathrm{E}} \mathrm{B}-\mathrm{Raf} /$ inhibitor complexes studied in the present work, the MMPBSA and MM-GBSA binding free energies were alternatively calculated as averages over the binding free energy values obtained from ten different $10 \mathrm{~ns}$ molecular dynamics trajectories using as starting point the corresponding minimized structures. Binding free energy values for each one of these trajectories were calculated over the full trajectory, and also over the last 5 ns. In both cases, the energy values were averaged 
over 100 snapshots extracted at a time interval of $10 \mathrm{ps}$ from each ns of the analyzed trajectory. The entropic contributions obtained as described in section 2.5 were used here.

\subsection{Pairwise free energy decomposition}

The contribution of each ${ }^{\mathrm{V} 600 \mathrm{E}} \mathrm{B}-\mathrm{Raf}$ protein residue to the total binding free energy of each complex was analyzed using the MM-GBSA decomposition protocol [45] implemented in the MMPBSA.py module of AmberTools12. The binding interaction for each residue-residue pair includes three terms: van der Waals contribution $\left(\Delta \mathrm{G}_{\mathrm{vdw}}\right)$, electrostatic contribution $\left(\Delta \mathrm{G}_{\text {ele }}\right)$ and solvation contribution $\left(\Delta \mathrm{G}^{\text {solv }}\right)$. The polar contribution of $\Delta \mathrm{G}^{\text {solv }}$ was computed as before using the generalized Born model based on the parameters developed by Onufriev et al [42]. All energy components were calculated using 500 snapshots corresponding to the last $5 \mathrm{~ns}$ of the full length molecular dynamics run.

\subsection{Analysis of the hydrogen bonds}

The hydrogen bonds established between the different ligands and the ${ }^{\mathrm{V} 600 \mathrm{E}} \mathrm{B}-\mathrm{Raf}$ protein were analyzed using the ptraj module of Ambertools12 over the last $5 \mathrm{~ns}$ of the MD. The parameters used to consider an interaction as a hydrogen bond were: (1) distance between the hydrogen acceptor and donor centers less than 3.5 $\AA$, and (2) acceptor-H-donor $\left(\theta_{\mathrm{HB}}\right)$ angle equal or greater than $120^{\circ}$. Values for the hydrogen bond angles are reported as $180-\theta_{\mathrm{HB}}$. The percentage of occupation quantifies the number of snapshots in which the conditions of distance and angle specified are satisfied.

\section{RESULTS AND DISCUSSION}

\subsection{Convergence of the MD simulations}

In order to analyze the structural stability of the modeled systems, as well as the convergence of each MD simulation, the root mean square deviation (rmsd) of the $\mathrm{C}_{\alpha}$ atomic positions was computed for each complex taking as reference the starting point for the MD simulations (Figure 2). However, prior to this analysis, the flexibility of each ${ }^{\mathrm{V} 600 \mathrm{E}} \mathrm{B}-\mathrm{Raf}$ amino acid was checked by computing the $\mathrm{C}_{\alpha}$ rmsf. Thus, those residues exhibiting the largest rmsf values, being therefore more flexible, were not considered for rmsd calculations. As expected, the maximum values of rmsf were obtained for those residues belonging to the modeled loop, being especially significant in the case of the 3 III 5 complex, which suggested us to extend the MD trajectory to $40 \mathrm{~ns}$ to ensure a reasonable degree of convergence.

The rmsf values obtained for each protein residue, except for those belonging to the modelled loop, are very similar for all studied complexes. This observation suggests that these inhibitors show a similar binding mechanism. As concerns the ligands, those belonging to the $1 \mathrm{UWJ}, 3 \mathrm{C} 4 \mathrm{C}$ and 3IDP crystallographic complexes 
show the lower mobilities (rmsd $<1 \AA$ ), whereas the 3II5 and 3Q96 crystallographic ligands show higher flexibility, although their rmsd remain around $1 \AA$ and become stabilized in the last $10 \mathrm{~ns}$ of molecular dynamics. As concerns protein rmsd values, they are, as expected, bigger than those for the ligands, although remaining low. A visualization of the MD movie allows concluding that the movement of the ligands is connected to the movement of the binding pocket showing parallel rmsd values,

\subsection{Binding Free Energy Calculations}

Reproducing absolute binding free energies is one of the most challenging problems in molecular modeling. Although different methodologies have been developed to this end, none of them is able to obtain binding free energies without requiring an enormous computational cost, thus preventing their use in standard drug-design projects $[46,47]$. In this work we have adopted the MM-PB/GBSA methodologies because they are computationally efficient, not restricted to closely related chemical structures, allow for rigorous total free energy decomposition and have been successfully applied in many cases [48-50]. However, it is worth to note that neither MM-PBSA nor MM-GBSA reproduce accurately the absolute experimental binding free energies, although fortunately, they have been proven to produce good correlations with experimental values [23].

In order to investigate the stability of the five studied complexes, MM-PBSA and MM-GBSA binding free energies $\left(\Delta \mathrm{G}_{\mathrm{b}}\right)$, calculated along the whole MD trajectory, were plotted as a function of time. As can be seen in Figure S1 (Supporting Information), the obtained plots show some differences. Thus, the 3C4C and 3IDP complexes exhibit a very fast convergence of both MM-PBSA and MM-GBSA energies while the 1UWJ and $3 \mathrm{II} 5$ complexes need about $5 \mathrm{~ns}$ to converge. Finally, about $10 \mathrm{~ns}$ are needed to stabilize the 3Q96 complex, which shows big fluctuations at the beginning of its MD trajectory.

The binding free energy values obtained within the MM-PBSA and MM-GBSA approaches are shown in Table 1. As can be seen, although the differences in the experimental $\Delta \mathrm{G}_{\mathrm{b}}$ values are small, both methods are able to distinguish the most potent inhibitors from the less potent ones. Moreover, the correlation between experimental and theoretical values is very good as we can see from the calculated $\mathrm{R}^{2}$ values: $0.79,0.85,0.69$, and 0.88 for the $\Delta \mathrm{G}_{\mathrm{GB}_{-} \text {total }}, \Delta \mathrm{G}_{\mathrm{PB}_{-} \text {total }}$ (without entropic contribution), $\Delta \mathrm{G}_{\mathrm{GB}}$ and $\Delta \mathrm{G}_{\mathrm{PB}}$ (with entropic contribution) calculations, respectively. We can note that the $\mathrm{R}^{2}$ value decreases for the GB method but slightly increases for the PB method when the entropy contribution is included. In any case, the PB approximation produces the best correlation.

The analysis of the different contribution terms to the total binding free energy (Table S1 of Supporting Information) allows one to conclude that the major driving forces during the formation of the ${ }^{{ }^{6} 60 \mathrm{E}} \mathrm{B}$-Rafinhibitor complexes are the van der Waals and non-polar solvation interactions $\left(\Delta \mathrm{G}_{\text {nonpolar, } \mathrm{PB} / \mathrm{GB}}+\Delta \mathrm{H}_{\mathrm{vdW}}\right)$. On the other hand, although the electrostatic interactions in gas phase positively contribute to the binding, the polarsolvation effect makes the total electrostatic contribution unfavorable $\left(\Delta \mathrm{G}_{\mathrm{polar}, \mathrm{PB} / \mathrm{GB}}+\Delta \mathrm{H}_{\mathrm{ee}}\right)$. The electrostatic contribution in gas phase is especially low for the $3 \mathrm{II} 5$ and $3 \mathrm{Q} 96$ complexes, probably due to the net charge of these ligands. In the case of 3II5, the binding free energy has an important contribution from the gas phase non- 
polar enthalpy $\left(\Delta \mathrm{H}_{\mathrm{vdW}}\right)$, which is compensated by a small gas phase polar enthalpy $\left(\Delta \mathrm{H}_{\mathrm{ee}}\right)$ and a big solvation penalty.

In order to improve our quantitative results, we adapted the recently suggested idea that a single long simulation may produce incorrect quantitative results due to inadequate sampling of conformational space, and thus multiple short simulations could better explore the conformational space than a single long simulation [51]. Consequently, each one of the minimized complexes (see Section 2.3) was subjected to ten $10 \mathrm{~ns}$ MD runs. Results are presented in Table 2. It can be seen that the use of ten short MD runs significantly increases the correlation with experimental data in the case of MM-GBSA $\left(\mathrm{R}^{2}=0.69\right.$ versus $\left.\mathrm{R}^{2}=0.86\right)$, while the opposite happens in the case of MM-PBSA $\left(\mathrm{R}^{2}=0.88\right.$ versus $\left.\mathrm{R}^{2}=0.82\right)$. In general, binding free energy values obtained from the multiple dynamics calculations using only the last $5 \mathrm{~ns}$ or the full length (10 ns) simulation time are very similar. Only the $3 \mathrm{Q} 96$ system, which needs more than $10 \mathrm{~ns}$ to be stabilized, presents important differences between these two approaches. On the other hand, differences between binding free energies obtained using averaged values from multiple MD runs or obtained from one long MD run are not very important, although they are case and method dependent. Thus, focusing in the differences between $\Delta \mathrm{G}_{\mathrm{X}}$ and $\Delta \mathrm{G}_{\mathrm{X} \text { mean_10 }}$ (where $\mathrm{X}$ refers to the PB or GB approaches), these are in all cases higher for MM-PBSA than for MM-GBSA. The maximum difference is observed for MM-PBSA in the case of the 3Q96 system (32.6\%) and the minimum (3.2\%) for the 3 II5 one. For MM-GBSA the maximum and minimum differences are obtained for 3Q96 (19.8\%) and 3IDP $(1.1 \%)$, respectively.

Taking these results together, we can conclude that for these systems multiple short molecular dynamics runs do not always improve the predicted binding free energies, unlike previous findings pointed out [52]. However, if a particular system needs more than $10 \mathrm{~ns}$ to achieve energetic stabilization, the methodology should be adapted in such a way that these multiple molecular dynamics runs were run for a longer simulation time in order to improve molecular sampling or even a case adaptive length, depending on the convergence of each studied system, should be used.

\subsection{Hydrogen bond analysis}

Hydrogen bonds, although being basically electrostatic in nature, have an important contribution to the bioactive structures of protein-ligand complexes due to its directionality requirements. The most important hydrogen bond interactions found from an analysis of the last $5 \mathrm{~ns}$ of the $\mathrm{MD}$ of the ${ }^{\mathrm{V}}{ }^{600 \mathrm{E}} \mathrm{B}$-Raf-inhibitor complexes are shown in Table 3 and Figure 3. In Figure S2 (Supporting Information), the ligand atoms involved in these interactions are schematically represented.

In all the studied complexes, residue F595 points away from the cavity during the whole trajectory. This orientation (DFG-out) is favored by the hydrogen bond network established between the protein and the ligand in this part of the cavity. In all cases, the ligand forms a hydrogen bond with the amide nitrogen of D594 (Figure 3). An additional hydrogen bond is formed between the ligand and the side chain oxygen of E501 in all complexes but $3 \mathrm{C} 4 \mathrm{C}$. In this case, the ligand establishes a second interaction with the carbonyl oxygen of D594. The lack of interaction with E501 in this complex can be attributed to the loss of planarity produced by the presence of a sulfonamide moiety. However, it is important to note that regardless of whether E501 interacts or 
not with the ligand, the side chain of this residue appears always hydrogen bonded to the amino group of residue K483. Also remarkable is the fact that, independently of the size and nature of the linker located at the same position that the urea group of Sorafenib (PDB Id. 1UWJ), the interaction of an acceptor atom of the ligand and the amide nitrogen of residue D594 is maintained across the series of ${ }^{\mathrm{V} 600 \mathrm{E}} \mathrm{B}$-Raf-inhibitor complexes. In the case of the 3Q96 complex, the inhibitor forms an additional hydrogen bond with the side chain of D594. This hydrogen-bond network may contribute to the stabilization of the DFG-out conformation of ${ }^{\mathrm{V} 600 \mathrm{E}} \mathrm{B}-\mathrm{Raf}$.

A second hydrogen bond zone is located around the hinge region (Figure 3). In this region, the interaction with residue C532 seems to play a critical role in the potency of these compounds. The three most active compounds (3C4C, 3Q96 and 3IDP) are hydrogen bonded to the backbone $\mathrm{N}$ atom of residue $\mathrm{C} 532$. Thus, 3C4C uses the $\mathrm{N}$ atom of the 7-azaindole ring, 3IDP its purine moiety and 3Q96 its bicycle pyridine lactam moiety. Moreover, in the case of 3Q96 and 3IDP, the presence of an additional hydrogen bond involving the carbonyl oxygen atom of this cysteine residue improves their potency. Finally, $3 \mathrm{C} 4 \mathrm{C}$ also presents a hydrogen bond between the $\mathrm{NH}$ group of its azaindole ring and the Q530 residue.

Taken together, these results suggest that the hydrogen bonds established between each ligand and D594 and E501 residues, as well as the intramolecular one established between K483 and E501 play a critical role in the inhibitory potency of these compounds. Moreover, although interaction of each ligand with residue C532 is not needed for activity (see 1UWJ and 3II5), it can significantly improve the inhibitor potency by establishing one or two hydrogen bonds.

\subsection{Pairwise Binding Free Energy Decomposition}

In order to achieve a better understanding of the interactions involved in the binding process, the contribution of each ${ }^{\mathrm{V} 600 \mathrm{E}} \mathrm{B}$-Raf residue to the total binding free energy of all five complexes was analyzed using the MM-GBSA decomposition protocol [45]. Figure 4 shows those residues having a contribution to the total binding free energy lower than $-1 \mathrm{kcal} / \mathrm{mol}$ for at least one of the systems in order to compare the same residues in the five analyzed complexes. As in many other kinases, Type II ${ }^{{ }^{6} 00 \mathrm{E}} \mathrm{B}$-Raf inhibitors bind to a long and narrow pocket, where they establish numerous protein-ligand contacts. In this scenario, and as can be seen in Figure 4, the binding free energy of the different complexes can be expressed as the sum of the contributions of many individual residues.

The protein residues that show the highest contribution to the binding free energy of the complexes are precisely those establishing hydrogen bonds with the ligand (Figures 3,4). These residues are: (1) E501, which contributes in more than $-5 \mathrm{kcal} / \mathrm{mol}$ to the formation of the complex. An exception is the $3 \mathrm{C} 4 \mathrm{C}$ complex, in which there is no hydrogen bond between this residue and the ligand; (2) D594, which in all cases appears hydrogen bonded to the ligand. The contribution of this residue to the binding free energy is larger in the case of 3C4C and 3Q96 due to the formation of an additional hydrogen bond with the ligand; (3) C532, whose contribution increases in those complexes where it forms hydrogen bond interactions with the ligand (i.e., 3C4C, 3 Q96 and 3IDP) and; (4) I463 and Q530, whose binding energy contribution for 3II5 and 3C4C is due to the formation of a hydrogen bond with the ligand. 
To gain insight into the structural requirements that a Type II inhibitor must fulfil to achieve optimal interactions with the ${ }^{\mathrm{V} 600 \mathrm{E}} \mathrm{B}$-Raf protein, and therefore, to improve its potency, we will focus our discussion on the interactions identified in the 3IDP complex, which shows the strongest binding energy. These interactions will be systematically compared in a further step with those found in the other complexes studied in the present work.

Complex 3IDP. The interactions found relevant in 3IDP can be summarized as follows: (1) the purine ring, which forms a bidentate hydrogen bond with the amide nitrogen and carbonyl oxygen of C532 (Figure 3), interacts with F583 and W531 through a $\pi-\pi$ parallel stacking (Figure 5a); (2) the pyridine ring interacts with I463 and V471 at the ATP-binding pocket and with E600, F595, V471 and K483 (Figure 5b) but not with residue L597 as in the crystallographic complex. The loss of this interaction is due to the different orientation adopted by this leucine residue during the MD; (3) the N-substituted ring of the isoquinoline moiety forms a hydrogen bond with the amide nitrogen of D594, interacts with residues L514 and T529 and forms a $\pi-\pi$ perpendicular stacking with F595 (Figure 5b). The methyl substituted ring of this moiety also interacts with T529 and is involved in a $\pi$-cation interaction with K483 while the methyl group of the isoquinoline moiety establishes hydrophobic contacts with A481 and T529; (4) the NH group that links the isoquinoline group with the terminal 4-chlorophenyl ring forms a hydrogen bond with the $\mathrm{O}$ side chain of D501 and (5) 4-chlorophenyl ring mainly interacts with L505, I513 and V504. Finally, it is worth to mention that the 3IDP crystal structure shows a water molecule involved in a hydrogen bridge between the ligand, D594 and K483. However, any attempt to keep this water molecule in its crystal position failed in the initial minimization steps.

Complex 1UWJ vs. 3IDP. Figure S3 (Supporting information) shows the ligands 3IDP and 1UWJ superimposed in the binding site of ${ }^{\mathrm{V} 600 \mathrm{E}} \mathrm{B}$-Raf and Figure 3 shows their interactions with the binding site residues. As can be seen, the most important structural differences between them are the replacement of the purine and isoquinoline moieties of 3IDP by a single aromatic ring in $1 \mathrm{UWJ}$, and the elimination of the pyridine ring linking both moieties with the subsequent shortening of this linker. These modifications result in a drop of the contribution of residues K483, T529, W531 and C532 (Figure S4). In the 1UWJ complex, K483 and W531 are not involved in $\pi$-stacking interactions with the ligand. Furthermore, C532 does not form any direct intermolecular hydrogen bond, although one between its amide nitrogen and the $\mathrm{N}$ atom of the pyridine ring has been observed in the crystallographic structure [3]. This interaction has been replaced in our MD simulation by a water mediated hydrogen bond (Figure S5). On the other hand, the methyl amide moiety located in this part of the cavity increases the contribution of residue I463 to the binding of 1UWJ.

The orientation adopted by residue E501 in the 1UWJ complex, facilitated by the bifurcated hydrogen bond that is formed between its $\mathrm{O}$ side chain and the two $\mathrm{N}$ atoms of the urea linker, maximizes its interaction with the ligand and, therefore, its contribution to complex formation. Similarly, the different orientation adopted by the 4-chloro-3-trifluorobenzyl moiety of $1 \mathrm{UWJ}$ compared with the corresponding one of 3IDP increases the contribution of residues H574 and D594. 
Complex $3 I I 5$ vs. 3IDP. As in the case of $1 \mathrm{UWJ}$, the structural differences between these two ligands can be used to explain the different binding energies of their complexes with ${ }^{\mathrm{V} 600 \mathrm{E}} \mathrm{B}-\mathrm{Raf}$. The non-substituted aromatic ring of 3 III5 is placed in the same region as the isoquinoline moiety of 3IDP, but with a slightly different orientation (Figure S3, Supporting Information). This fact, together with the presence of a single aromatic ring instead of a bicyclic system, hampers the $\pi$ - stacking interactions between the ligand isoquinoline moiety and residues K483 and F595 seen in 3IDP. The close residues A481, T529 and G593 present an important change in their contributions to the binding energy and the structural changes in the binding site also affect D594, which adopts a conformation that maximizes its interaction with the ligand in the 3 III 5 complex. The pyrazolo[1,5-a]pyrimidine group is placed and oriented similarly to the pyridine group of 3IDP (Figure S3). However, its bigger size favors the interaction with the nearby residues I463, V471, L597 and E600, increasing their binding free energy contribution (Figure S4). The 4- $\mathrm{Ph}-\mathrm{CH}_{2}-\mathrm{NH}\left(\mathrm{CH}_{3}\right)_{2}{ }^{+}$group of 3II5 is placed in a region of the cavity unoccupied by 3IDP, thus increasing the contribution of V471, L597, E600 and S465 (Figure S4, Supporting Information). Moreover, the presence of a positively charged group in this region of the binding site favors the formation of a hydrogen bond with the carbonyl oxygen of I463, which has not been observed in the crystallographic structure [36]. However, by comparison with 3IDP, the orientation adopted by this 4- $\mathrm{Ph}-\mathrm{CH}_{2}-$ $\mathrm{NH}\left(\mathrm{CH}_{3}\right)_{2}{ }^{+}$group in 3 II5 implies a drop in the contribution of residues A481, W531 and C532 to the stability of the 3 III complex. Finally, the orientation adopted by the trifluoromethylphenyl group is very similar to that observed for the corresponding ring in the 1UWJ complex, which translates into a drop in the contribution of I513 and L514 and an increase of H574 and D576.

Complex $3 C 4 C$ vs. 3IDP. The binding of $3 \mathrm{C} 4 \mathrm{C}$ to ${ }^{\mathrm{V} 600 \mathrm{E}} \mathrm{B}-\mathrm{Raf}$ shows the following differences as compared with 3IDP: (1) the orientation adopted by the azaindole group, placed in the same region as the purine ring of 3IDP, allows the formation of two hydrogen bonds between the N1 and N7 atoms and residues Q530 and C532, respectively (Figure 3) [34]. The ability of 3C4C to form a hydrogen bond with Q530, a characteristic unique to this compound, accounts for the higher contribution of this residue to the stability of the complex; (2) the presence of a chlorine atom in position 5 of the azaindole moiety reinforces the interaction of the ligand with residue I463, increasing its binding free energy contribution; (3) the smaller size and slightly different orientation of the difluorophenyl ring of $3 \mathrm{C} 4 \mathrm{C}$ in comparison to the isoquinoline ring of 3IDP (Figure S3), decreases the contribution of residues A481,K483, T529 and F595 (Figure S4); (4) the carbonyl oxygen and amide nitrogen of D594 are hydrogen bonded to the $\mathrm{N}$ and $\mathrm{O}$ atoms of sulfonamide, increasing its contribution to the binding free energy of the complex; (5) in contrast to the 3IDP complex, residue E501 is not hydrogen bonded to the ligand, making its contribution lower; (6) the hydrophobic propyl group cannot achieve the same interactions as the aromatic chlorophenyl moiety of 3IDP with residues I513, I592 and G593, hence decreasing their contribution; (7) it can be observed a decrease in the contribution of E600 due to the lack of interaction with the pyridine moiety of 3IDP, absent in the 3C4C ligand.

Complex 3IDP vs. 3Q96. Although 3IDP and 3Q96 have similar activity, there are many structural differences between them. First, the pyridine cycle of 3IDP is not present in 3Q96, producing a decrease in the contributions of residues V471, E600 and F595. The methyl group of the isoquinoline moiety is also missing in 
3Q96, causing now a drop in the contribution of A481 and K483. Moreover, although the isoquinoline moiety of 3IDP and the tetrahydronaphthalene group of 3Q96 have the same size and are placed in the same region within the binding site, their different orientation modifies the contribution of the surrounding residues to the formation of the respective complexes. Thus, L514 and T529 contribute less in the 3Q96 complex (Figure S4). Similarly, the different orientation adopted by the trifluoromethylphenyl distal ring of 3Q96, as compared with the equivalent chlorophenyl group in 3IDP, diminishes the contribution of G593 and I513. This is not the case for the indole and the bicyclic pyridine lactam in the ATP-binding region of 3IDP and 3Q96, respectively, which show a similar interaction pattern (Figure S3). One of the most relevant features of the 3Q96 complex is that the methylamino group of the fluorinated ring occupies an additional region of the binding site, increasing the contribution of residues H574 and D576. Also remarkable is the enhanced contribution of residues E501 and D594 in the 3Q96 complex as compared to 3IDP. All the other contributions, being in their vast majority of hydrophobic character, show the opposite trend. Thus, it can be suggested that in order to obtain the directional interactions of these charged residues and to establish good hydrogen bonds with the 3Q96 ligand, a global hydrophobic destabilization is needed.

\subsection{Structural requirements for ${ }^{\mathrm{V} 600 \mathrm{E}} \mathrm{B}$-Raf inhibition}

The results obtained in the present work show that the formation of a hydrogen bond network involving the ligand and protein residues D594, E501 and K483 plays a critical role in the stabilization of the DFG-out conformation of ${ }^{\mathrm{V} 600 \mathrm{E}} \mathrm{B}$-Raf by inhibitor binding. In all the complexes studied, the ligand forms a hydrogen bond with the amide nitrogen of D594. Although most of the inhibitors studied here are also hydrogen bonded to the side chain oxygen of E501, this interaction seems not to be critical for activity. Thus, the 3C4C ligand does not interact with this glutamic, being however an active inhibitor. Yet, regardless of whether E501 interacts or not with the ligand, this residue appears always hydrogen bonded to K483. On the other hand, the complexes of the three most active compounds show a hydrogen bond with C532. Although this interaction does not seem to be essential for activity (1UWJ and 3II5 have activities in the nM range without exhibiting this interaction), its presence leads to an increase of activity.

Also hydrophobic interactions have a significant role in the inhibition of ${ }^{\mathrm{V} 600 \mathrm{E}} \mathrm{B}-\mathrm{R}$ af. Our results appear to indicate that the ligands have to display at least three features: (1) an hydrophobic (or aromatic) group, located in the zone occupied by the 4-chlorophenyl moiety of 3IDP, which interacts with V504 and L505; (2) an hydrophobic group, preferably aromatic, to allow a $\pi$-cation stacking interaction with K483, which would also interact with residues V471, A481, L514, T529 and F595 and, (3) an aromatic group, placed near the pyridine moiety of 3IDP and close to the last mentioned hydrophobic group, interacting with I463 and F583. Moreover, the presence of an additional hydrophobic feature, located nearby the 4-chlorophenyl moiety of 3IDP, able to interact with L567 and I572, could increase the inhibitory potency of the compounds. 


\section{CONCLUSIONS}

In this work, the energetics and structural keys of the binding of five different inhibitors to the oncogenic protein ${ }^{{ }^{600} \mathrm{E}} \mathrm{B}-\mathrm{Raf}$ in its DFG-out conformation have been studied using MD and free energy calculations. The results obtained show that the binding free energy of these complexes is due to the individual contribution of many residues distributed throughout the binding site of the protein. Among them, those residues involved in the formation of hydrogen bonds show the highest contribution. Specifically, residues K483, D594 and E501 have been found to play a critical role in the inhibition of ${ }^{\mathrm{V} 600 \mathrm{E}} \mathrm{B}-\mathrm{Raf}$. In all the cases, D594 is hydrogen bonded to the ligand, whereas E501 is intramolecularly bonded to K483. The interaction of this glutamic residue with the ligand, observed in most of the studied complexes, seems not to be critical for activity. In fact, 3C4C lacks this interaction and is still highly active. It has been found for residue C532 that its interaction through hydrogen bond with the ligand leads to an increase in the activity of the compound. On the other hand, three different hydrophobic features of the ligands have been found critical for activity. These features, distributed along the cavity, are located near the chlorophenyl, isoquinoline and pyridine moieties of the 3IDP ligand. For these last two, the incorporation of an aromatic moiety favors the $\pi$-stacking interaction with residues K483 and F595. The incorporation of a fourth hydrophobic interaction accounting for the 4-chloro substituent of 3IDP is expected to increase the inhibitory potency of these compounds.

\section{CONFLIC OF INTEREST}

The authors confirm that this article content has no conflicts of interest.

\section{ACKNOWLEDGEMENTS}

This work was supported by Ministerio Español de Ciencia y Tecnología (project CTQ2011-29285C02-01 and 02) and the Generalitat of Catalunya (project 2014SGR1017). We thank Patricia Gómez-Gutierrez and Prof. J.J. Pérez González, from the UPC, for doing the MOE calculations.

\section{REFERENCES}

[1] Davies, H.; Bignell, G. R.; Cox, C.; Stephens, P.; Edkins, S.; Clegg, S.; Teague, J.; Wo endin, H.; Garnett, M. J.; Bottomley, W.; Davis, N.; Dicks, E.; Ewing, R.; Floyd, Y.; Gray, K.; Hall, S.; Hawes, R.; Hughes, J.; Kosmidou, V.; Menzies, A.; Mould, C.; Parker, A.; Stevens, C.; Watt, S.; Hooper, S.; Wilson, R.; Jayatilake, H.; Busterson, B. A.; Cooper, C.; Shipley, J.; Hargrave, D.; Pritchard-Jones, K.; Maitland, N.; Chenevix-Trench, G.; Riggins, G. J.; Bigner, D. D.; Palmieri, G.; Cossu, A.; Flanagan, A.; Nicholson, A.; Ho, J. W. C.; Leung, S. Y.; Yuen, S. T.; Weber, B. L.; Seigler, H. F.; Darrow, T. L.; Paterson, H.; Marais, R.; Marshall, C. J.; Wooster, R.; Stratton, M. R.; Futreal, P. A. Mutations of the BRAF gene in human cancer. Nature, 2002, 417, 949-954.

[2] Gray-Schopfer, V.; Wellbrock, C.; Marais, R. Melanoma biology and new targeted therapy. Nature, 2007, $445,851-857$.

[3] Wan, P. T. C.; Garnett, M. J.; Roe, S. M.; Lee, S.; Niculescu-Duvaz, D.; Good, V. M.; Cancer Genome Project; Jones, C. M.; Marshall, C. J.; Springer, C. J.; Barford, D.; Marais, R. Mechanism of Activation of the RAF-ERK Signaling Pathway by Oncogenic Mutations of B-RAF. Cell, 2004, 116, 855-867. 
[4] Xu, M.; Yu, L.; Wan, B.; Yu, L.; Huang, Q. Predicting Inactive Conformations of Protein Kinases Using Active Structures: Conformational Selection of Type-II Inhibitors. PLoS ONE, 2011, 6, e22644.

[5] Liu, Y.; Gray, N. S. Rational design of inhibitors that bind to inactive kinase conformations. Nature Chem. Biol., 2006, 2, 358-364.

[6] Li, H.; Chen Y.; Rao, S.; Chen, X.; Liu, H.; Qin, J.; Tang, W.; Ye-Wang, Zhou, X., Lu, T. Recent Advances in the Research and Development of B-Raf Inhibitors. Curr. Med. Chem., 2010, 17, 1618-1634.

[7] Liu, L.; Cao, Y. C.; Chen, C.; Zhang, X. M.; McNabola, A.; Wilkie, D.; Wilhelm, S.; Lynch, M.; Carter, C. Sorafenib blocks the RAF/MEK/ERK pathway, inhibits tumor angiogenesis, and induces tumor cell apoptosis in hepatocellular carcinoma model PLC/PRF/5. Cancer Res., 2006, 66, 11851-11858.

[8] Omar, M.; Khan, F.; Ramos, C. L. An Update on BRAF Inhibitors and Other New Molecular Targets for the Treatment of Malignant Melanoma of the Skin. Clin. Med. Insights: Dermatology, 2013, 6, 1-7.

[9] Flaherty, K. T.; Puzanov, I.; Kim, K. B.; Ribas, A.; McArthur, G. A.; Sosman, J. A.; O’Dwyer, P. J.; Lee, R. J.; Grippo, J. F.; Nolop, K.; Chapman, P. B. Inhibition of Mutated, Activated BRAF in Metastatic Melanoma. $N$. Engl. J. Med., 2010, 363, 809-819.

[10] Trunzer, K.; Pavlick, A. C.; Schuchter, L; Gonzalez, R.; McArthur, G. A.; Hutson, T. E.; Moschos, S. J.; Flaherty, K. T.; Kim K. B.; Weber, J. S.; Hersey, P.; Long, G. V.; Lawrence, D.; Ott, P. A.; Amaravadi, R. K.; Lewis, K. D.; Puzanov, I.; Lo, R. S; Koehler, A.; Kockx, M.; Spleiss, O.; Schell-Steven, A.; Gilbert, H. N.; Cockey, L; Bollag, G.; Lee, R. J.; Joe, A. K.; Sosman, J. A.; Ribas, A. Pharmacodynamic Effects and Mechanisms of Resistance to Vemurafenib in Patients With Metastatic Melanoma. J. Clin. Onc., 2013, 31, $1767-$ 1774.

[11] Huang, T.; Karsy, M.; Zhuge, J.; Zhong, M.; Liu, D. B-Raf and the inhibitors: from bench to bedside. J. Hem. \& Onc., 2013, 6:30.

[12] Pinto, M.; Orzaez, M.Delgado-Soler, L.; Pérez, JJ.; Rubio-Martínez, J. Rational design of new class of BH3-mimetics as inhibitors of the Bcl-x $\mathrm{L}_{\mathrm{L}}$ protein. J. Chem. Inf. Model., 2011, 51, 1249-1258.

[13] Obiol-Pardo, C.; Alcarraz-Vizán, G.; Cascante, M.; Rubio-Martínez, J. Diphenyl urea derivatives as inhibitors of transketolase: a structure-based virtual screening. PLOS ONE. 2012, 7, e32276.

[14] Steve Wenglowsky, S,; Ren , L.; Grina, J.; Hansen, JD.; Laird, ER.; Moreno, D.; Dinkel, V.; Gloor, SL.; Hastings, G.; Rana, S.; Rasor, K.; Sturgis, HL.; Voegtli, VC.; Vigers, G.; Willis, B.; Mathieu, S.; Rudolph, J.; Highly potent and selective 3-N-methylquinazoline-4(3H)-one based inhibitors of B-Raf ${ }^{\mathrm{V} 600 \mathrm{E}}$ kinase. Bioorganic \& Medicinal Chemistry Letters., 2014, 24, 1923-1927

[15] Vasbinder, MM.; Aquila, B.; Augustin, B.; Chen, H.; Cheung, T.; Cook, D.; Drew, L. et al. Discovery and Optimization of a Novel Series of Potent Mutant B-Raf ${ }^{\mathrm{V} 600 \mathrm{E}}$ Selective Kinase Inhibitors. J. Med. Chem., 2013, 56, 1996-2015

[16] Ren, L.; Ahrendt, KA.; Grina, J.; Laird, ER.; Buckmelter, AJ.; Hansen , JD.; et al. The discovery of potent and selective pyridopyrimidin-7-one based inhibitors of B-Raf ${ }^{\mathrm{V} 600 \mathrm{E}}$ kinase. Bioorganic \& Medicinal Chemistry Letters. 2012, 22, 3387-3391

[17] Packard, GK.; Papa, P.; Riggs, JR.; Erdman, P.; Tehrani, L.; Robinson, D.; Harris, R. et al. Discovery and optimization of thieno[2,3-d]pyrimidines as B-Raf inhibitors. Bioorganic \& Medicinal Chemistry Letters. 2012, 22, 747-752.

[18] Yang, S.; Li, QS.; un, S.; Zhang, YB.; Wang, XL.; Zhang, F.; Tang, JF.; Zhu, HL. Design, modification and 3D QSAR studies of novel 2,3-dihydrobenzo[b][1,4]dioxin-containing 4,5-dihydro-1H-pyrazole derivatives as inhibitors of B-Raf kinase. Bioorganic \& Medicinal Chemistry. 2012, 20,6048-6058. 
[19] F. Baska,F.; Szabadkai,I.; Sipos, A.; Breza, N.; Szántai-Kis, C.; Kékesi, L.; Garamvölgyi, R.; Nemes, Z.; Baska, f.; Neumann, L.; Torka, R.; Ullrich, A.; Kéri, G.; .Orfi, L. Pharmacophore and Binding Analysis of Known and Novel B-RAF Kinase Inhibitors. Current Medicinal Chemistry, 2014, 21, 1938-1955

[20] Caballero, J.; Alzate-Morales, JH.; Vergara-Jaque, A. Investigation of the Differences in Activity between Hydroxycycloalkyl N1 Substituted Pyrazole Derivatives As Inhibitors of B-Raf Kinase by Using Docking, Molecular Dynamics, QM/MM, and Fragment-Based De Novo Design: Study of Binding Mode of Diastereomer Compounds. J. Chem. Inf. Model., 2011, 51, 2920-2931

[21] Alzate-Morales, J. H.; Vergara-Jaque, A.; Caballero, J. Computational Study on the Interaction of N1 Substituted Pyrazole Derivatives with B-Raf Kinase: An Unusual Water Wire Hydrogen-Bond Network and Novel Interactions at the Entrance of the Active Site. J. Chem. Inf. Model., 2010, 50, 1101-1112.

[22] Chung, JY,; Chung, HW.; Cho, SJ.; Hah, JM.; Cho, AE.; QM/MM based 3D QSAR models for potent BRaf inhibitors. J. Comput. Aided Mol. Des., 2010, 24, 385-397.

[23] Yang,Y.; Qin, J.; Liu, H.; Yao, X. Molecular Dynamics Simulation, Free Energy Calculation and Structure-Based 3D-QSAR Studies of B-RAF Kinase Inhibitors. J. Chem. Inf. Model., 2011, 51, 680-692.

[24] Wang, ZJ.; Wan, ZN.; Chen, XD.; Wu ,CF.; Ga, GL.; Liu, R.; Shi,Z.; Bao, JK. In silico identification of novel kinase inhibitors by targeting B-Rafv660e from natural products database. J.Mol.Model., 2015, 21,102

[25] Shih, KC.; Lin, CY.; Zhou, J.; Chi, HC.; Chen, TS.; Wang, CC.; Tseng, HW.; Tan, CY. Development of Novel 3D-QSAR Combination Approach for Screening and Optimizing B-Raf Inhibitors in silico. J. Chem. Inf. Model,. 2011, 51, 398-407.

[26] Yang,Y.; Qin, J.; Liu, H.; Yao, X. Molecular Dynamics Simulation, Free Energy Calculation and Structure-Based 3D-QSAR Studies of B-RAF Kinase Inhibitors. J. Chem. Inf. Model., 2011, 51, 680-692.

[27] Shih, KC.; Lin, CY.; Zhou, J.; Chi, HC.; Chen, TS.; Wang, CC.; Tseng, HW.; Tan, CY. Development of Novel 3D-QSAR Combination Approach for Screening and Optimizing B-Raf Inhibitors in silico. J. Chem. Inf. Model., 2011, 51, 398-407.

[28] Hornak, V.; Abel, R.; Okur, A.; Strockbine, B.; Roitberg, A.; Simmerling, C. Comparison of multiple Amber force fields and development of improved protein backbone parameters. Proteins: Struct., Funct. Bioinf., 2006, 65,712-725.

[29] Wang, J.M.; Wolf, R.M.; Caldwell, J.W.; Kollman, P.A.; Case, D.A. Development and testing of a general amber force field. J. Comput. Chem., 2004, 25, 1157-1174.

[30] Case, D.A.; Darden, T.A.; Cheatham III T.E.; Simmerling, C.L.; Wang,J.; Duke, R.E.; Luo, R.; Walker, R.C.; Zhang, W.; Merz, K.M.; Roberts, B.P.; Wang,B.; Hayik, S.; Roitberg, A.; Seabra, G.; Kolossváry, I.; Wong, K.F.; Paesani, F.; Vanicek, J.; Liu, J.; Wu, X.; Brozell, S.R.; Steinbrecher, T.; Gohlke, H.; Cai, Q.; Ye, X.; Wang, J.; Hsieh, M.J.; Cui, G.; . Roe, D.R.; Mathews, D.H.; Seetin, M.G.; Sagui, C.; Babin,V.; Luchko, T.; Gusarov, S.; Kovalenko, A.; Kollman, P.A. 2010, AMBER 11. San Francisco. University of California.

[31] Darden, T.; York, D.; Pedersen, L. Particle mesh Ewald: An N . $\log (\mathrm{N})$ method for Ewald sums in large systems. J. Chem. Phys., 1993, 98, 10089-10092.

[32] Jorgensen, W.L.; Chandrasekhar, J.; Madura, J.D.; Impey, R.W.; Klein, M.L. Comparison of Simple Potential Functions for Simulating Liquid Water. J. Chem. Phys., 1983, 79, 926-935.

[33] Delano, W.L. The PyMOL Molecular Graphics System, Version 099rc6.

[34] Tsai, J.; Lee, J.T.; Wang, W.; Zhang, J.; Cho, H.; Mamo, S.; Bremer, R.; Gillette, S.; Kong, J.; Haass, N.K.; Sproesser, K.; Li, L.; Smalley, K.S.; Fong, D.; Zhu, Y.L.; Marimuthu, A.; Nguyen, H.; Lam, B.; Liu, J.; Cheung, I.; Rice, J.; Suzuki, Y.; Luu, C.; Settachatgul, C.; Shellooe, R.; Cantwell, J.; Kim, S.H.; Schlessinger, J.; Zhang, K.Y.; West, B.L.; Powell, B.; Habets, G.; Zhang, C.; Ibrahim, P.N.; Hirth, P.; Artis, D.R.; Herlyn, M.; Bollag, G. 
Discovery of a selective inhibitor of oncogenic B-Raf kinase with potent antimelanoma activity. Proc. Natl. Acad. Sci. USA, 2008, 105, 3041-3046.

[35] Smith, A. L.; Demorin, F. F.; Paras, N. A.; Huang, Q.; Petkus, J. K.; Doherty, E. M.; Nixey, T.; Kim, J. L.; Whittington, D. A.; Epstein, L. F.; Lee, M. R.; Rose, M. J.; Babij, c.; Fernando, M.; Hess K.; Le, Q.; Beltran, P.; Carnahan, J. Selective Inhibitors of the Mutant B-Raf Pathway: Discovery of a Potent and Orally Bioavailable Aminoisoquinoline. J. Med. Chem., 2009, 52, 6189-6192.

[36] Berger, D. M.; Torres, N.; Dutia, M.; Ciszewski, G.; Gopalsamy, A.; Levin, J. I.; Kim, K.; Xu, W.; Wilhelm, J.; Hu, Y.; Collins, K.; Feldberg, L.; Kim, S.; Frommer, E.; Wojciechowicz, D.; Mallon, R. Non-hingebinding pyrazolo[1,5-a]pyrimidines as potent B-Raf kinase inhibitors. Bioorg. Med. Chem. Lett., 2009, 19, 65196523.

[37] Gould, A. E.; Adams, R.; Adhikari, S.; Aertgeerts, K.; Afroze, R.; Blackburn, C.; Calderwood, E. F.; Chau, R.; Chouitar, J.; Duffey, M. O.; England, D. B.; Farrer, C.; Forsyth, N.; Garcia, K.; Gaulin, J.; Greenspan, P.D.; Guo, R.; Harrison, S. J.; Huang, S.; Iartchouk, N.; Janowick, D.; Kim, M.; Kulkarni, B.; Langston, S. P.; Liu, J. X.; Ma, L.; Menon, S.; Mizutani, H.; Paske, E.; Renou, C. C.; Rezaei, M.; Rowland, R. S.; Sintchak, M. D.; Smith, M. D.; Stroud, S. G.; Tregay, M.; Tian, Y.; Veiby, O. P.; Vos, T. J.; Vyskocil, S.; Williams, J; Xu, T.; Yang, J. J.; Yano, J.; Zeng, H.; Zhang, D. M.; Zhang, Q.; Galvin, K. M. Design and optimization of potent and orally bioavailable tetrahydronaphthalene Raf inhibitors. J. Med. Chem., 2011, 54, 1836-1846.

[38] Molecular Operating Environment [MOE], 2013.08; Chemical Computing Group Inc., 1010 Sherbooke St. West, Suite \#910, Montreal, QC, Canada, H3A 2R7, 2013.

[39] Humphrey, W.; Dalke, A.; Schulten, K. VMD: visual molecular dynamics. J. Mol. Graph., 1996, 14, $33-38$.

[40] Nagar, B.; Bornmann, W. G.; Pellicena, P.; Schindler, T.; Veach D. R.; Miller W. T.; Clarkson, B.; Kuriyan, Crystal Structures of the Kinase Domain of c-Abl in Complex with the Small Molecule Inhibitors PD173955 and Imatinib (STI-571). J. Cancer Res., 2002, 62, 4236-4243.

[41] Berendsen, H. J. C.; Postma, J. P. M.; van Gunsteren, W. F.; DiNola, A.; Haak, J. R. Molecular dynamics with coupling to an external bath. J. Chem. Phys., 1984, 81, 3684-3690.

[42] Onufriev, A.; Bashford, D.; Case, D. A. Exploring protein native states and large-scale conformational changes with a modified generalized born model. Proteins, 2004, 55, 383-394.

[43] Kuhn, B.; Gerber, P.; Schulz-Gasch, T.; Stahl, M. Validation and use of the MM-PBSA approach for drug discovery. J. Med. Chem., 2005, 48, 4040-4048.

[44] Gohlke, H.; Case, D.A. Converging free energy estimates: MM-PB(GB)SA studies on the protein-protein complex Ras-Raf. J. Comput. Chem., 2004, 25, 238-250.

[45] Gohlke, H.; Kiel, C.; Case, D. A. Insights into protein-protein binding by binding free energy calculation and free energy decomposition for the Ras-Raf and Ras-RalGDS complexes. J. Mol. Biol., 2003, 330, 891-913.

[46] Lybrand, T.; McCammon, J. A.; Wipff, G. Theoretical calculation of relative binding affinity in host-guest systems. Proc. Natl. Acad. Sci. USA, 1986, 83, 833-835.

[47] Christ, C. D., A. E. Mark, and W. F. van Gunsteren. Basic ingredients of free energy calculations: A review. J. Comput. Chem., 2010, 31, 1569-1582.

[48] Xu, Y.; Wang, R. A computational analysis of the binding affinities of FKBP12 inhibitors using the MMPB/SA method. PROTEINS: Struct., Funct. Bioinf., 2006, 64, 1058-1068.

[49] Hou, T.; Wang, J.; Youyong Li, Y.; Wang, W. Assessing the performance of the MM/PBSA and MM/GBSA methods. 1. The accuracy of binding free energy calculations based on molecular dynamics simulations. J. Chem. Inf. Model., 2011, 51, 69-82. 
[50] Meher, B.R.; Wang, Y. Interaction of I50V Mutant and I50L/A71V Double Mutant HIV-Protease with Inhibitor TMC114 (Darunavir): Molecular Dynamics Simulation and Binding Free Energy Studies. J. Phys. Chem. B, 2012, 116, 1884-1900.

[51] Sadiq, S. K.; Wright, D. W.; Kenway, O. A.; Coveney, P. W. Accurate ensemble molecular dynamics binding free energy ranking of multidrug-resistant HIV-1 proteases. J. Chem. Inf. Model., 2010, 50, 890-905.

[52] Laura Delgado-Soler, L; Marta Pinto, M.; Tanaka-Gil, K.; Rubio-Martinez, J. Molecular Determinants of Bim(BH3) Peptide Binding to Pro-Survival Proteins. J. Chem. Inf. Model., 2012, 52, 2107-2118. 
Figure 1. Structures of the five B-Raf inhibitors studied in this work.

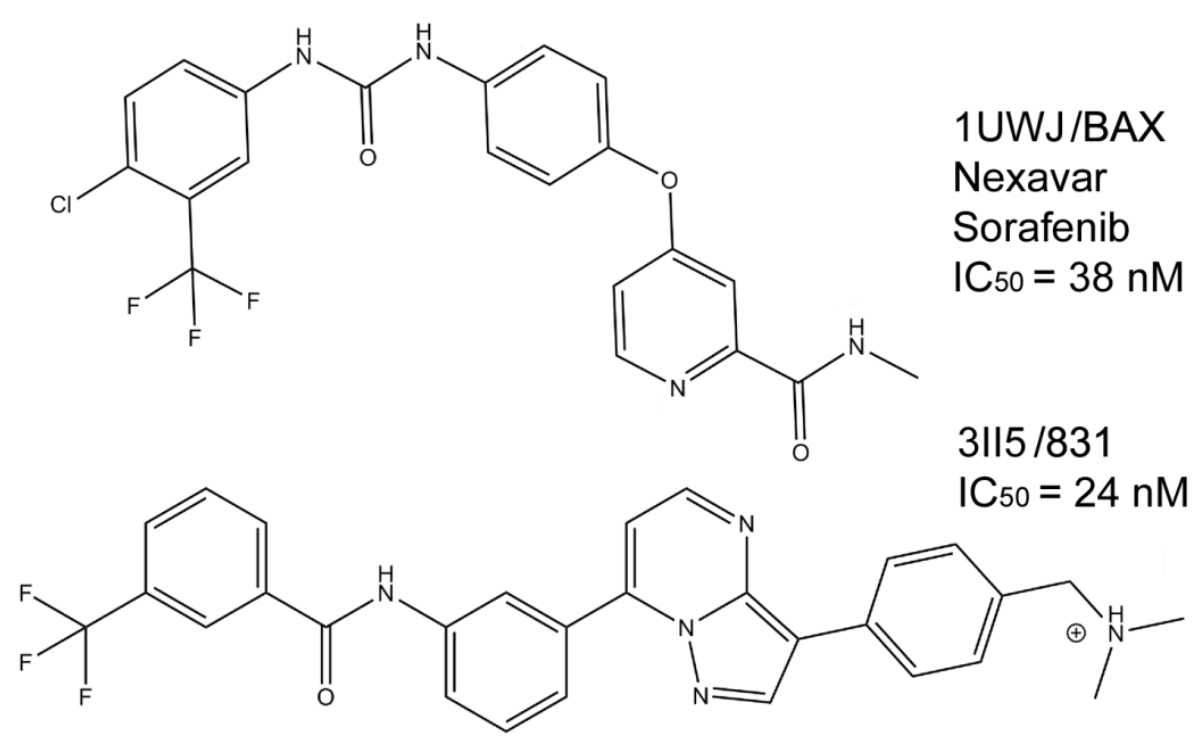

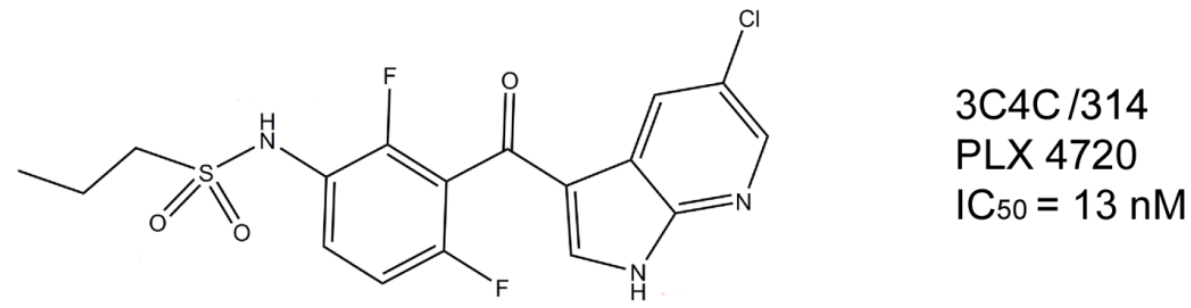<smiles>CC(C)(N)c1cc(NC(=O)C2CCc3ccc(Oc4ccnc5c4CCC(=O)N5)cc3C2)cc(C(F)(F)F)c1</smiles><smiles>Cc1ccc2c(Nc3ccc(Cl)cc3)nccc2c1Nc1ncccc1-c1ncnc2[nH]cnc12</smiles> 
Figure 2. The RMSD values as a function of the simulation time of the $\mathrm{C} \alpha$ protein atoms, ligand atoms and binding pocket, the latter defined by those protein residues within $4.5 \AA$ of any ligand atom, for: (a) 1UWJ, (b) 3II5, (c) 3C4C, (d) 3Q96 and (e) 3IDP (f) RMSF of each residue of the protein for all five complexes obtained from $30 \mathrm{~ns}$ of molecular dynamics simulation.
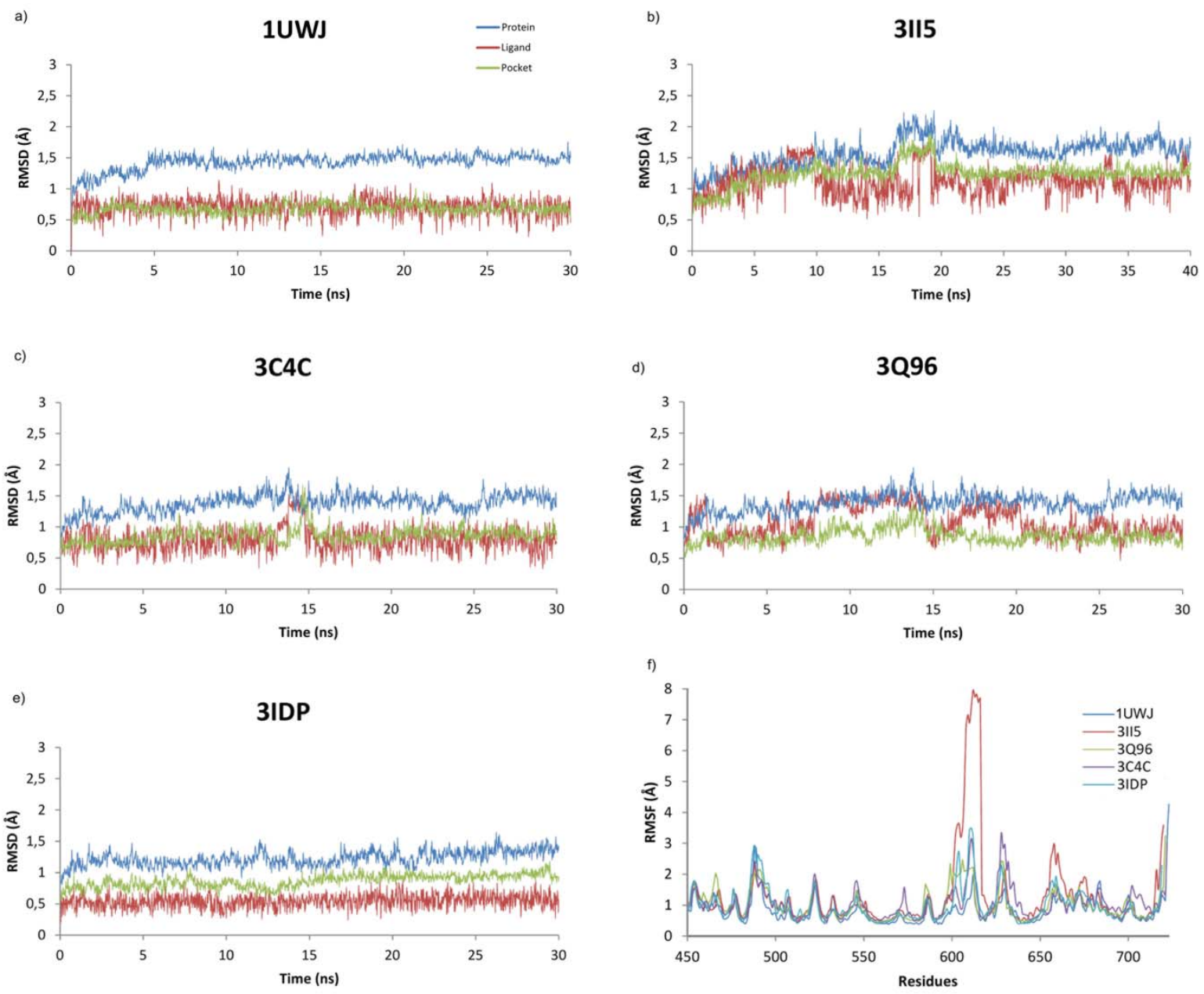
Figure 3. Structure comparison between representative snapshots from the last ns MD of: (a) 1UWJ, (b) 3II5, (c) 3C4C, (d) 3Q96, and (e) 3IDP complexes at the active site of B-Raf with its corresponding inhibitor.

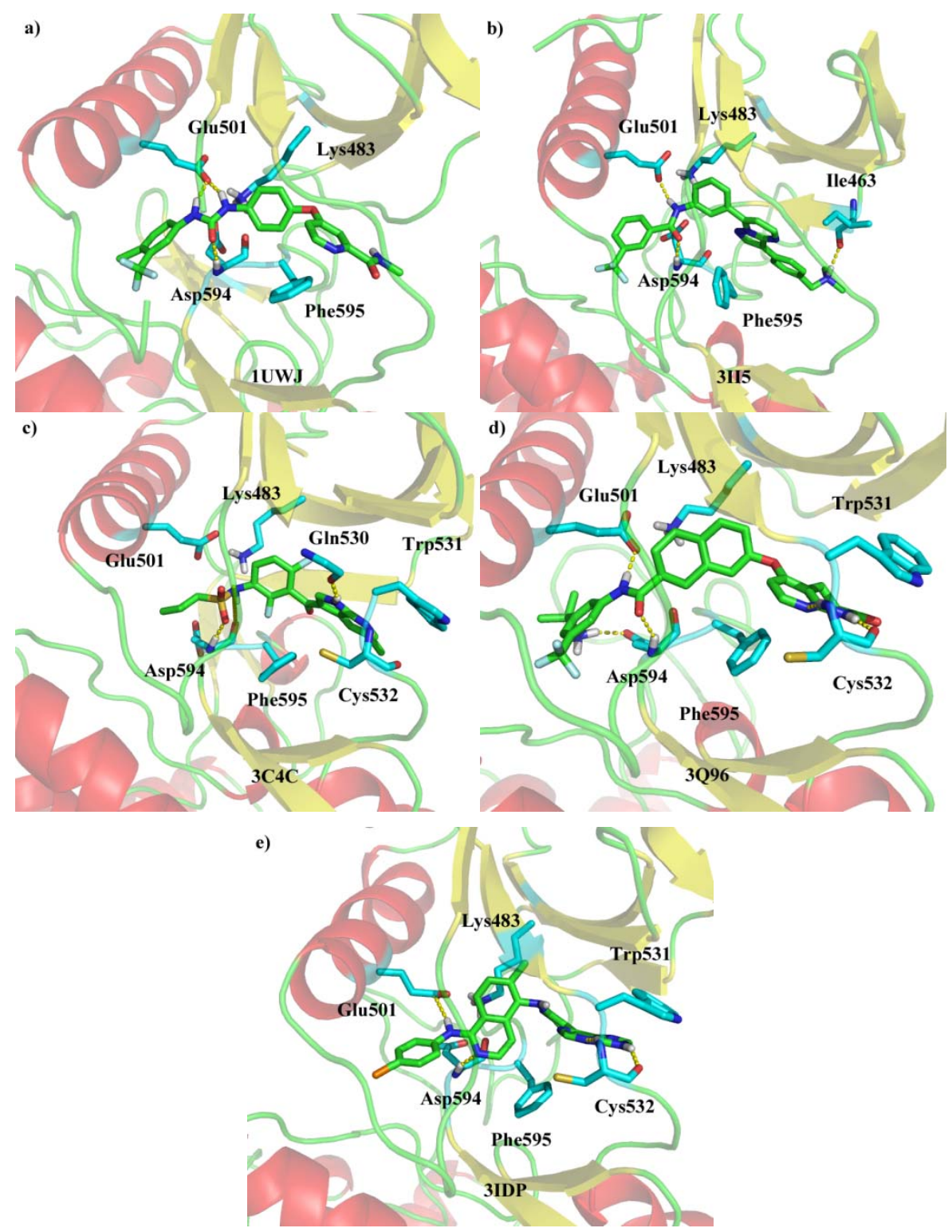


Figure 4. Contribution of key residues of B-Raf to the total binding free energy for the systems: 1UWJ, 3II5, 3C4C, 3Q96, and 3IDP.

\section{UWJ}

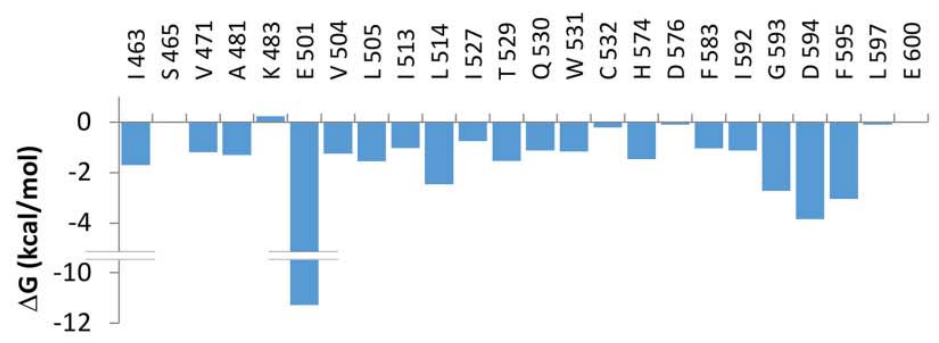

3115

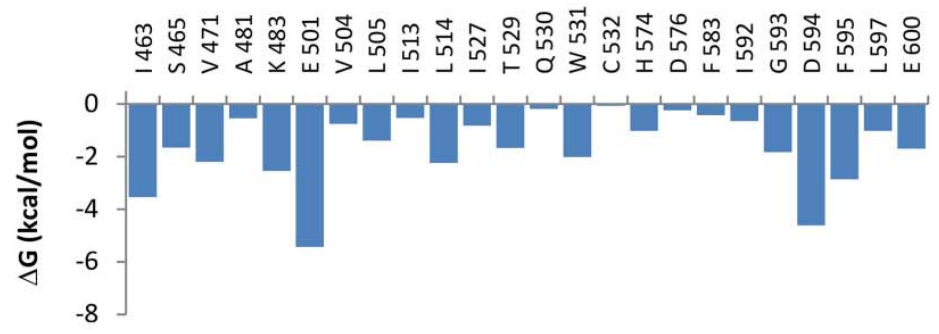

3C4C

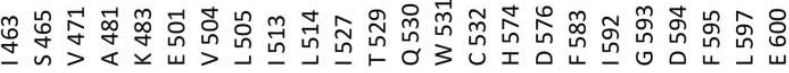

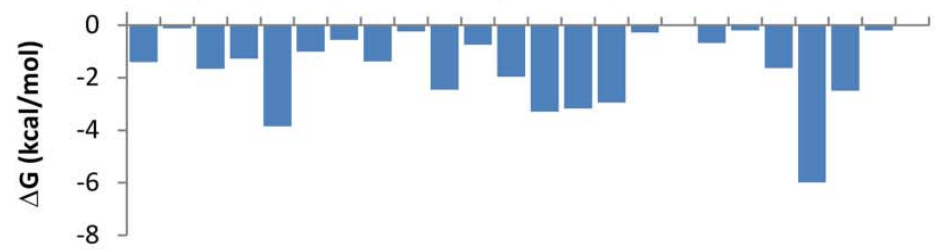

$3 Q 96$

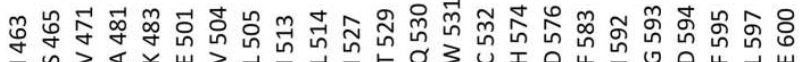

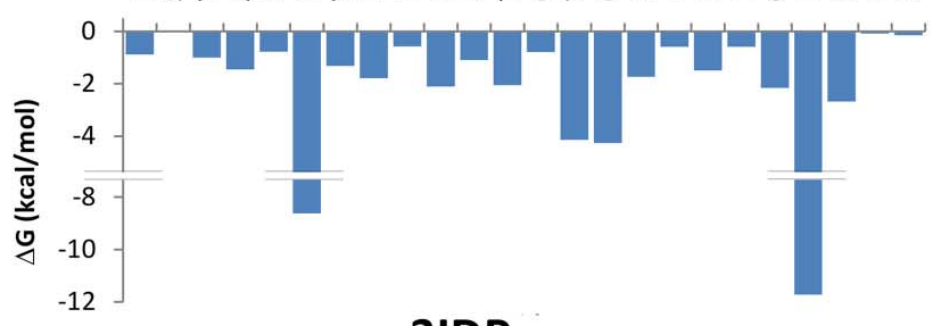

3IDP

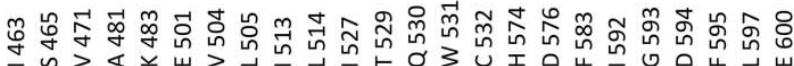

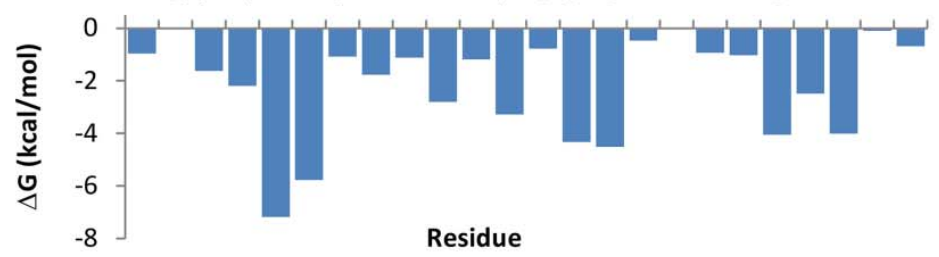


Figure 5. 3IDP/B-Raf interaction pattern. a) and b) are related by a rotation of $180^{\circ}$ around the perpendicular axis.

a)

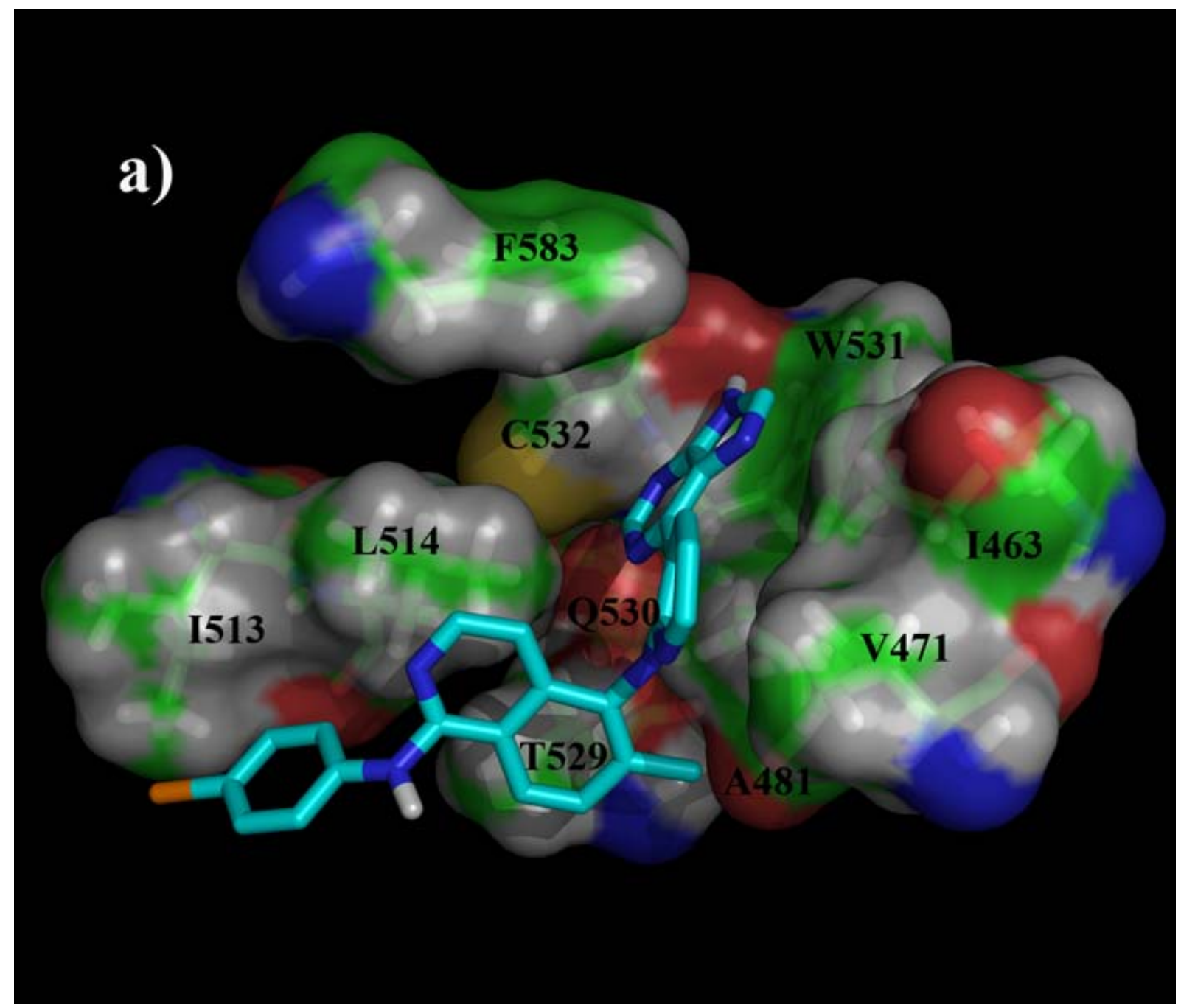


b)

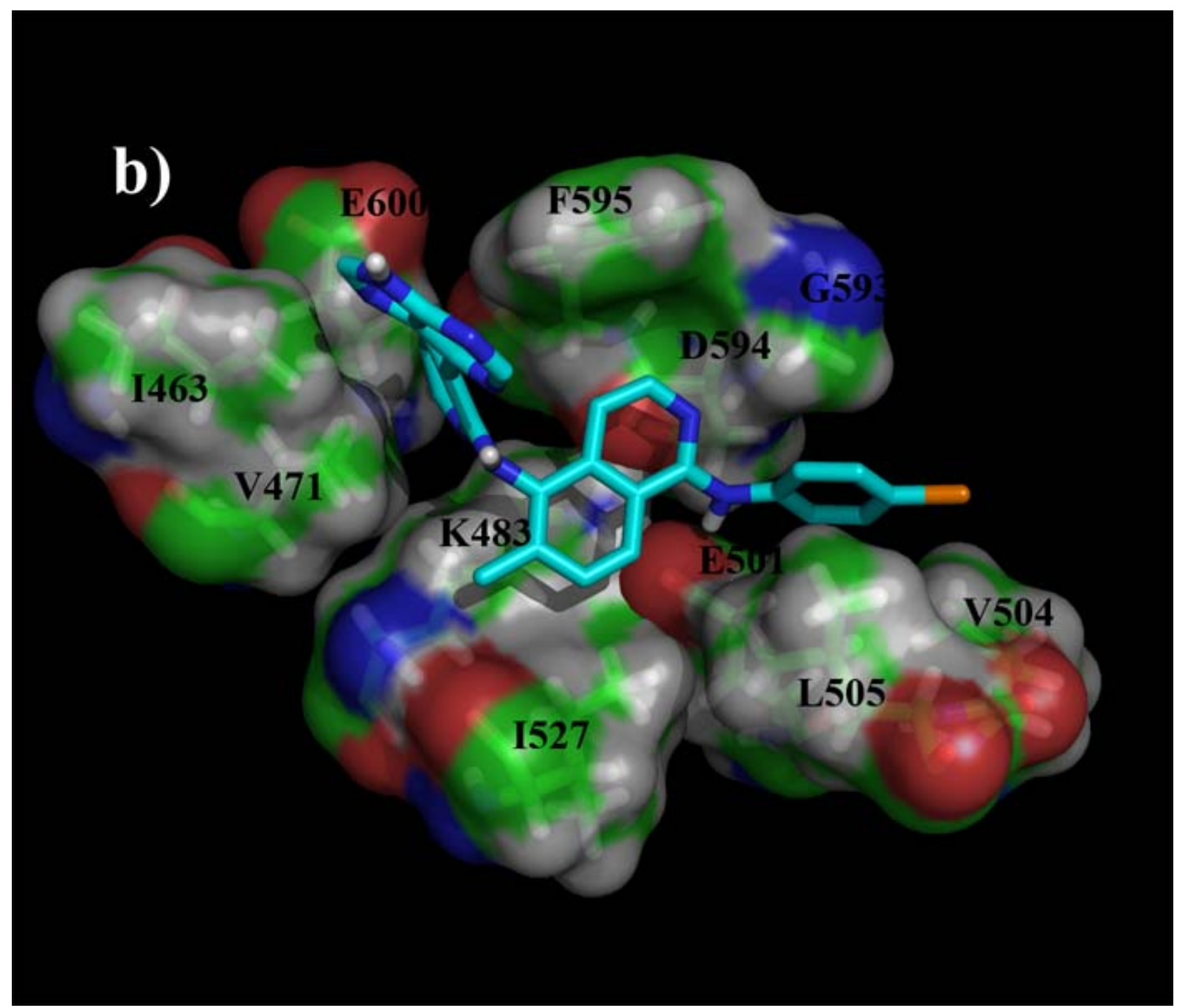


Table 1. Binding free energies $(\mathrm{kcal} / \mathrm{mol})$ and their different contributions for the studied Ligand/B-Raf complexes averaged over the last $5 \mathrm{~ns}$ of molecular dynamics. In this Table, $\Delta \mathrm{H}_{\mathrm{vdw}}$ and $\Delta \mathrm{H}_{\mathrm{ee}}$ are the van der Waals and electrostatic molecular mechanics energies; $\Delta \mathrm{G}_{\text {polar_X }}$ and $\Delta \mathrm{G}_{\text {nonpolar_X }}$ represent the electrostatic and nonpolar contributions to the solvation free energy respectively and $\Delta \mathrm{G}_{\mathrm{X}}=\Delta \mathrm{G}_{\mathrm{X}_{-} \text {total }}-\mathrm{T} \Delta \mathrm{S}$, with $\mathrm{X}$ being the GB or PB method. Experimental $\mathrm{IC}_{50}$ values were obtained from references 3,20-23 for 1UWJ, 3C4C, 3IDP, 3II5, 3Q96 respectively.

\begin{tabular}{|c|c|c|c|c|c|}
\hline System & 1UWJ & $3 I I 5$ & $3 \mathrm{C} 4 \mathrm{C}$ & $3 Q 96$ & 3IDP \\
\hline$\Delta \mathbf{H}_{\mathrm{vdW}}$ & -56.96 & -64.20 & -47.95 & -65.38 & -70.33 \\
\hline$\Delta \mathbf{H}_{\mathrm{ee}}$ & -30.66 & -11.92 & -34.89 & -4.18 & -47.45 \\
\hline$\Delta \mathbf{G}_{\text {polar_PB }}$ & 52.17 & 45.32 & 47.87 & 26.26 & 65.50 \\
\hline$\Delta G_{\text {nonpolar_PB }}$ & -6.45 & -7.15 & -5.69 & -7.64 & -6.61 \\
\hline$\Delta \mathbf{G}_{\text {polar_GB }}$ & 43.64 & 31.07 & 39.59 & 16.71 & 52.10 \\
\hline$\Delta \mathbf{G}_{\text {nonpolar_GB }}$ & -7.79 & -8.23 & -6.34 & -8.46 & -7.07 \\
\hline$\Delta G_{P B \_t o t a l}$ & -41.89 & -37.95 & -40.66 & -50.94 & -58.89 \\
\hline$\Delta \mathbf{G}_{\mathbf{G B}_{\text {_total }}}$ & -51.77 & -53.29 & -49.59 & -61.31 & -72.74 \\
\hline$-\mathbf{T} \Delta \mathbf{S}$ & 21.06 & 17.13 & 18.88 & 23.59 & 24.52 \\
\hline$\Delta \mathbf{G}_{\mathrm{PB}}$ & -20.83 & -20.82 & -21.78 & -27.35 & -34.37 \\
\hline$\Delta \mathbf{G}_{\mathrm{GB}}$ & -30.71 & -36.16 & -30.71 & -37.72 & -48.22 \\
\hline $\mathrm{IC}_{50}(\mathrm{nM})$ & 38 & 24 & 13 & 2.9 & 1.6 \\
\hline$\Delta \mathbf{G}_{\exp }$ & -10.12 & -10.39 & -10.75 & -11.64 & -11.99 \\
\hline
\end{tabular}


Table 2. Binding free energies ( $\mathrm{kcal} / \mathrm{mol}$ ), including the entropic contribution, calculated with the MM-PBSA and MM-GBSA approaches using the last $5 \mathrm{n}$ of the full molecular dynamics run $\left(\Delta \mathrm{G}_{\mathrm{X}}\right)$, the mean of the total length of ten $10 \mathrm{~ns}$ molecular dynamics $\left(\Delta \mathrm{G}_{\mathrm{X} \_ \text {mean_10 }}\right)$ or the mean of the last $5 \mathrm{~ns}$ of the ten $10 \mathrm{~ns}$ molecular dynamics $\left(\Delta \mathrm{G}_{\mathrm{X}_{-} \text {mean_5 }}\right)$ for the different Ligand/B-Raf complexes, being $\mathrm{X}$ equal to PB or GB methods.

\begin{tabular}{|c|c|c|c|c|c|c|}
\hline System & $1 \mathrm{UWJ}$ & $3 I I 5$ & $3 \mathrm{C} 4 \mathrm{C}$ & 3 Q96 & 3IDP & $\overline{\mathbf{R}^{2}}$ \\
\hline$\Delta \mathbf{G}_{\mathrm{PB}}$ & -20.83 & -20.82 & -21.78 & -27.35 & -34.37 & 0.88 \\
\hline$\Delta \mathbf{G}_{\mathrm{PB}_{-} \text {mean_5 }}$ & $-26,97$ & -20.10 & -24.00 & -33.43 & -41.98 & 0.76 \\
\hline$\Delta \mathbf{G}_{\mathrm{PB} \_ \text {mean_10 }}$ & -27.16 & -20.16 & -25.76 & -36.28 & -42.78 & 0.82 \\
\hline$\Delta \mathbf{G}_{\mathbf{G B}}$ & -30.71 & -36.16 & -30.71 & -37.72 & -48.22 & 0.69 \\
\hline$\Delta \mathbf{G}_{\mathbf{G B}_{-} \text {mean_5 }}$ & -32.72 & -32.57 & -29.54 & -41.91 & -48.08 & 0.81 \\
\hline$\Delta \mathbf{G}_{\mathbf{G B}_{-} \text {mean_10 }}$ & -32.50 & -31.83 & -30.08 & -45.21 & -47.69 & 0.86 \\
\hline$\Delta \mathbf{G}_{\text {exp }}$ & -10.12 & -10.39 & -10.75 & -11.64 & -11.99 & \\
\hline
\end{tabular}


Table 3. Hydrogen bonds with an occupancy greater than $30 \%$ obtained from the last $5 \mathrm{~ns}$ of the MD trajectory. Average distances and angles are also shown (standard deviation in parenthesis)

\begin{tabular}{llllll}
\hline \multirow{2}{*}{ System } & \multicolumn{1}{c}{ Donor } & Acceptor & Occupancy(\%) & Distance( $\mathbf{\AA})$ & Angle ( $)$ \\
\hline 1UWJ & D594 HN & ligand O15 & 100.0 & $2.91(0.13)$ & $24.0(10.5)$ \\
& ligand HN14 & E501 OE2 & 100.0 & $2.91(0.15)$ & $32.2(9.1)$ \\
& ligand HN12 & E501 OE2 & 100.0 & $2.82(0.11)$ & $23.7(8.5)$ \\
& K483 HN & I527 O & 100.0 & $3.00(0.15)$ & $24.5(10.8)$ \\
& K483 HNZ1 & D594 O & 50.4 & $2.80(0.10)$ & $22.4(11.7)$ \\
& K483 HNZ3 & E501 OE2 & 50.0 & $2.85(0.13)$ & $25.1(13.1)$ \\
& K483 HNZ3 & E501 OE1 & 42.8 & $3.04(0.17$ & $39.2(12.2)$ \\
\hline 3II5 & D594HN & ligand O1 & 82.4 & $3.03(0.15)$ & $21.3(11.1)$ \\
& ligand H55 & E501 OE1 & 86.0 & $3.01(0.18)$ & $25.6(8.5)$ \\
& ligand HN1 & I463 O & 59.6 & $2.92(0.16)$ & $24.5(13.3)$ \\
& K483 HNZ2 & E501 OE2 & 68.4 & $2.85(0.13)$ & $26.0(10.4)$ \\
& K483 HNZ1 & E501 OE1 & 60.8 & $2.90(0.15)$ & $43.2(9.8)$ \\
& K483 HNZ2 & E501 OE1 & 31.2 & $2.87(0.12)$ & $24.3(12.2)$ \\
\hline 3C4C & ligand HN7 & Q530 O & 100.0 & $2.84(0.11)$ & $18.33(9.8)$ \\
& D594 HN & ligand O23 & 99.6 & $2.91(0.14)$ & $21.0(10.7)$ \\
& C532 HN & ligand N4 & 96.0 & $3.07(0.15)$ & $21.0(11.5)$ \\
& ligand HN21 & D594 O & 94.0 & $3.02(0.19)$ & $22.5(9.7)$ \\
& K483 HNZ1 & E501 OE1 & 38.4 & $2.75(0.09)$ & $21.7(10.1)$ \\
& K483 HNZ2 & E501 OE1 & 33.2 & $2.75(0.08)$ & $20.8(10.8)$ \\
\hline 3IDP & ligand HN24 & E501 OE1 & 100.0 & $2.90(0.14)$ & $14.11(7.2)$ \\
& D594 HN & ligand O23 & 97.6 & $3.00(0.17)$ & $23.53(11.7)$ \\
& C532 HN & ligand N2 & 94.8 & $3.04(0.14)$ & $29.42(13.8)$ \\
& K532 HN & ligand N6 & 96.8 & $2.99(0.12)$ & $25.7(14.0)$ \\
& ligand HN33 & C532 O & 94.4 & $2.99(0.17)$ & $25.7(12.8)$ \\
& D594 HN & ligand N23 & 79.6 & $2.98(0.11)$ & $41.1(12.4)$ \\
& K483 HNZ2 & D594 O & 34.8 & $2.78(0.10)$ & $24.7(12.6)$ \\
& ligand HN7 & C532 O & 92.0 & $3.10(0.19)$ & $17.0(10.7)$ \\
& K483 HNZ1 & E501 OE2 & 45.6 & $2.81(0.11)$ & $24.9(13.6)$ \\
& K483 HNZ2 & E501 OE2 & 40.0 & $2.83(0.13)$ & $22.7(11.9)$ \\
& K483 HNZ1 & E501 OE1 & 34.0 & $3.07(0.22)$ & $40.9(12.4)$ \\
\hline & E501 OE2 & 34.0 & $2.77(0.10)$ & $27.8(10.7)$ \\
& & & &
\end{tabular}

